\title{
On the Feasibility of Unlicensed Communications in the TV White Space: Field Measurements in the UHF Band
}

\author{
M. Fadda, ${ }^{1}$ V. Popescu, ${ }^{2}$ M. Murroni, ${ }^{3}$ P. Angueira, ${ }^{4}$ and J. Morgade ${ }^{4}$ \\ ${ }^{1}$ Cagliari Research Unit, Italian University Consortium for Telecommunications, 09123 Cagliari, Italy \\ ${ }^{2}$ Department of Electronics \& Computers, Transilvania University of Brașov, 500019 Brașov, Romania \\ ${ }^{3}$ Department of Electrical and Electronic Engineering, University of Cagliari, 09123 Cagliari, Italy \\ ${ }^{4}$ Department of Communications Engineering, UPV/EHU, Alda Urkijo S/N, 48013 Bilbao, Spain
}

Correspondence should be addressed to V. Popescu; vlad.popescu@unitbv.ro

Received 29 September 2014; Revised 20 January 2015; Accepted 3 February 2015

Academic Editor: Jintao Wang

Copyright (C) 2015 M. Fadda et al. This is an open access article distributed under the Creative Commons Attribution License, which permits unrestricted use, distribution, and reproduction in any medium, provided the original work is properly cited.

\begin{abstract}
In practical unlicensed communications in TV band, radio devices have to identify, at first, the transmission opportunities, that is, the portion of the spectrum licensed for broadcasting services unoccupied in a certain region at certain time, that is, the socalled TV white space. In this paper the outcome of field measurements in the UHF TV band (470-860 MHz) conducted in EU is presented. To obtain empirical values for the parameters upon which unlicensed radio devices are able to distinguish in a real scenario between empty and occupied TV channels, signal power measurements have been performed in Italy, Spain, and Romania on rural, suburban, and urban sites, at different heights over the ground by using different analysis bandwidths. The aim of this work is to provide a set of practical parameters upon which harmless unlicensed communication in the UHF TV white space is feasible. The results have been analyzed with respect to the hidden node margin problem, spectrum sensing bandwidth, and occupancy threshold.
\end{abstract}

\section{Introduction}

The current global move to switch from analogue to digital TV has opened up an opportunity for the reallocation of this valuable resource. In one way, spectrum bands once used for analogue TV broadcasting will be completely cleared, leaving a space for deploying new licensed wireless services, and, in another way, digital television technology geographically interleaves spectrum bands to avoid interference between neighboring stations, leaving a space for deploying new unlicensed wireless services.

The complete transition from analogue to the digital TV was planned in Europe for 2012. After analogue switchoff the spectrum $790 \mathrm{MHz}$ to $862 \mathrm{MHz}$ (TV channels 61 to 69 ), the so-called digital dividend, was entirely cleared from broadcast. Within the remaining spectrum $(470 \mathrm{MHz}$ to $790 \mathrm{MHz}$ ) not all channels are occupied at each location, due to coverage limits in network planning. These locally unused channels are called TV white space (TVWS) [1].

A number of the requirements to operate in TVWS are based on cognitive radio technology including location awareness and spectrum sensing [1]. These new regulatory rules open up an opportunity to develop new wireless networks to utilize this spectrum. However, access to this new spectrum also comes with some technical challenges.

There are a number of other requirements also that are intended to provide protection for the licensed services that operate in the TV bands. These requirements impose technical challenges for the design of devices operating in TVWS spectrum.

In the UHF band, the presence of digital terrestrial television (DTT) services [2] can be revealed by considering the information included in geolocation databases (GL-DBs) [3] if available, which provide for a certain location the list of the free DTT channels and the allowable maximum radiated power to transmit without harmful interference to DTT users $[1,4]$.

Studies $[5,6]$ conducted on compatibility problems in EU identified the joint use of local inspection of the spectrum by means of opportunistic detection techniques (i.e., spectrum sensing) [7-9] which can be also cooperative [10], multiband 
[11], and based on GL-DBs as a possible viable way to effective harmless unlicensed communications. A BBC study [12] identified the joint use of wideband spectrum sensing techniques, GL-DBs and transmission power control [13], to be effectively safe for TVWS communications. Further researches by the Electronic Communication Committee (ECC) [14] and the ITU-R [15] confirm this assumption.

A key issue for spectrum sensing operations is the evaluation of the so-called hidden node margin (HNM). The HNM is a parameter that quantifies the difference between the potential interfered signal (e.g., DTT signal) at the location where it is estimated by the unlicensed device and the actual signal at the location where the receiving antenna for this signal is located. HNM is critical to define the protection requirements unlicensed devices must comply with to avoid harmful interference to DTT receivers. Several studies have already analyzed the HNM problem based on empirical measurements. In [16] authors use data coming from a preliminary measurement campaign conducted in the same locations of the present study in Italy and partially in Spain to analyze the HNM with respect to man-made noise. In [17] the HNM related to the implementation of spectrum sensing algorithms in autonomous operation has been evaluated with two different methodologies: ray-tracing deterministic and statistical approaches. In [18] a way to determine the hidden node value through computer modeling, supported by validation measurements in real scenarios, is presented. In [19], a solution to the hidden-node problem for passivelistening receiver has been provided, considering that when passive listening, licensed receivers (i.e., DTT receivers) do not acknowledge or respond.

The majority of the studies focused on the spectrum occupancy without considering an in-depth analysis for the quantification of the HNM. For example, [20] describes spectrum occupancy measurements in the TV spectrum performed in Chengdu, China, and the results show the idle spectrum band which can be used by unlicensed devices. In [21] authors investigate the opportunities for the use of the TVWS spectrum in Malaysian urban areas depending on time and location: data has been collected from eight different urban areas in Malaysia to measure the spectrum occupancy and the received signal strength level. In [22] spectrum occupancy measurements carried out in three locations of the Kanto area in Japan are presented. The collected data, corresponding to the overage of the DTT broadcasting service, is analyzed to evaluate the possibilities of secondary systems operating in the TVWS within the framework of FCC regulations and the Japanese standards.

Another spectrum measurement campaign covering the frequency range from $75 \mathrm{MHz}$ to $7 \mathrm{GHz}$ both for indoor and for outdoor scenarios in urban and suburban locations in Barcelona, Spain, has been conducted in [23]. The measurements have been analyzed to determine the spectrum occupancy and compared to the official spectrum regulations defined by the governmental agency in charge of the frequency allocations in Spain. In [24] a spectral occupancy measurement campaign conducted for the frequency range between $806 \mathrm{MHz}$ and $2750 \mathrm{MHz}$ in urban areas of Auckland,
New Zealand, in order to identify potential spectral opportunities for unlicensed devices is described. Statistical results are presented in the form of noise distributions, signal amplitude probability distributions, and spectral occupancy rates as percentages of time. All these measurement campaigns have been performed in a specific country.

Further studies have considered more than one nation but investigating only one specific parameter. In [25], spectrum occupancy measurements conducted in the frequency range from $75 \mathrm{MHz}$ to $7075 \mathrm{MHz}$ are shown, demonstrating the low degree of spectrum use in an urban outdoor environment. In [26] a report on measurements carried out synchronously over the period of 48 hours in seven European cities is given. The authors mainly focused on harmonizing the measurement settings and equipment so as to obtain as comparable data as possible. In [27], a comparative study of two measurement campaigns carried out in Barcelona, Spain, and Poznan, Poland, to identify spectrum occupancy in different bands is presented.

Measurements of UHF TV band spectrum and fieldstrength levels before and after the analog switch-off in the cities of Thessaloniki (Greece) and Skopje (Republic of Macedonia) are presented in [28], showing the feasibility of opportunistic secondary spectrum utilization in extensive parts of the spectrum.

Unlike previous spectrum surveys which mainly focused on average spectrum occupancy, both fixed and mobile measurements in Beijing, China, have been performed in [29], focusing on the overall usage of TV bands. Multiple factors including frequency, time, space domain, and specific TV standards have been considered.

With respect to the above-mentioned studies, this paper analyzes experimental results obtained in three different countries around Europe: Spain, Italy, and Romania. The data is considered as a whole, in order to provide results that can be applicable in countries or regions with similar spectrum picture, network planning approaches, and regulation (i.e., the EU zone), but with different geography. The main goal of this paper is to produce a set of practical parameters upon which harmless unlicensed communication in the UHF TV bands can be feasible.

The three countries are representative for the gradual digital switchover in Europe: while at the time of the measurements Italy had already completed the passage to digital television, Spain was halfway in the process and Romania had a penetration of digital TV services of less than $20 \%$.

The work presented in this paper focuses on an extended spectral analysis of the UHF TV band performed to obtain realistic values of the following parameters: occupancy threshold, sensing bandwidth, man-made noise, and HNM. Through a carefully planned measurement campaign performed in different locations of the three European countries from 2011 to 2014, the current UHF radio noise has been studied and compared with realistic DTT receiver noise figures in relation to channel occupancy thresholds. The measurements over the entire UHF band allowed assessing the variability of HNM, now performed and analyzed at varying frequencies with respect to the preliminary results presented in [16]. A novelty of the present research is also 
TABLE 1: Characteristics of the measurement sites.

\begin{tabular}{lcccc}
\hline Code & Floors & Environment & Description & Altitude $(\mathrm{m})$ \\
\hline BI-00 & 4 & Urban & Office building & 30 \\
BI-01 & 7 & Urban & Office building & 36 \\
BI-02 & 2 & Rural & Rural house & 300 \\
BI-03 & 2 & Suburban & Flat building & 100 \\
CA-00 & 3 & Urban & Flat house & 10 \\
CA-01 & 2 & Suburban & Flat house & 5 \\
CA-02 & 3 & Suburban & Flat house & 5 \\
CA-03 & 1 & Rural & Rural house & 117 \\
CA-04 & 4 & Urban & Office building & 120 \\
CA-05 & 2 & Urban & Office building & 40 \\
BV-00 & 4 & Urban & Office building & 577 \\
BV-01 & 2 & Suburban & Flat building & 560 \\
BV-02 & 1 & Rural & Rural house & 545 \\
BV-03 & 3 & Urban & Office building & 550 \\
\hline
\end{tabular}

the analysis of the relevance of using smaller bandwidths (i.e., $1 \mathrm{MHz}$ and $100 \mathrm{kHz}$ ) on the accuracy of the spectrum sensing operation.

The rest of this paper is organized as follows. Section 2 describes the methodology and scenarios used for the measurements, the occupation threshold calculation, and the importance of the opportune selection of the sensing bandwidth. Section 3 presents the obtained results in terms of spectral occupancy and HNM statistics. Finally, Section 4 draws the conclusions.

\section{Methodology}

Occupancy threshold, sensing bandwidth, and HNM are the three main parameters that have been monitored during the measurements. Initially, the RF power received at the roof level has been evaluated for all DTT channels available in the UHF band and for each building, considering the fact that the DTT antennas are typically located at the roof level. Then, the received power was measured for all channels on each floor, also including void channels in order to quantify the electromagnetic noise level.

2.1. Measurement Scenarios and Methodology. The authors focused on choosing three different cities, with a similar orography and distribution of buildings in urban and suburban areas, to obtain comparable data. The measurements were carried out in and around the cities of Bilbao (Spain), Cagliari (Italy), and Braşov (Romania) in urban, suburban, and rural environments. The three countries differ in the usage of the TV bands and status of the digital switchover: while in Italy and Spain the DTT market is already mature, in Romania the DTT transmissions represent less than $20 \%$ of the entire over-the-air TV broadcasting because the digital switchover is scheduled to be completed only in June 2015. Table 1 summarizes the main characteristics of the measurement sites.

The three cities are characterized by urban and suburban areas displaced at different altitudes compared to the sea

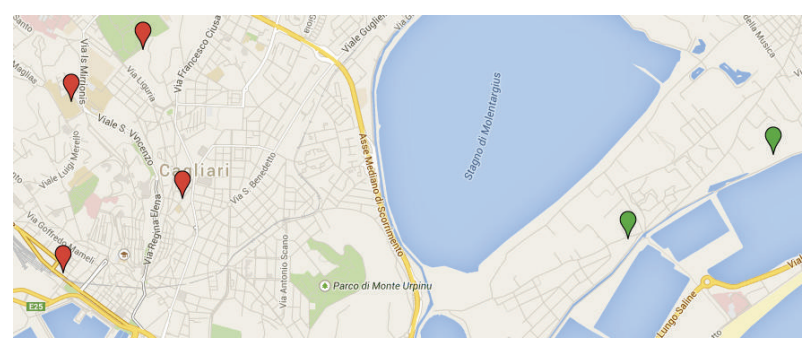

FIgURE 1: Measurement spots in Cagliari for urban (red marks) and suburban (green marks) environments.

level. For example, Figure 1 shows the locations of the measurements carried out in Sardinia, in different urban and suburban areas of the city of Cagliari.

The measurement system was composed of different types of antennas, field-strength meters, and vector signal analyzers. The main characteristics of the antennas are summarized in Table 2. The samples were normalized using the antennas calibration data. Table 3 shows the equipment noise floor data.

In order to obtain a precise analysis of the UHF band, the measurements were divided into three rounds of power measurements using different channel bandwidths. This allowed us to obtain a set of values for the received levels across the TV bands with three sensitivity thresholds. During the first round, RMS power values were collected using an $8 \mathrm{MHz}$ bandwidth filter channel, specific for DTT channels. The second and the third rounds have smaller bandwidths of the filter channel: $1 \mathrm{MHz}$ and $100 \mathrm{kHz}$, respectively.

A time limit of 20 seconds for gathering the RMS samples at each frequency was imposed to avoid unwanted effects such as the transient regime of the analyzer or hypothetical burst-like transmissions.

2.2. Occupancy Thresholds. The occupancy threshold is defined as the minimum power value measured by the cognitive device and used to decide whether an $8 \mathrm{MHz} \mathrm{TV}$ channel is occupied or free.

The filter bandwidth used for the measurements defines the measurement accuracy: the larger the bandwidth, the lower the accuracy. Considering the official occupancy data, three void channels across the UHF band were selected for each location. In Bilbao, the center frequencies of the considered void channels were 408,520 , and $834 \mathrm{MHz}$, respectively, in Cagliari 466, 658, and $842 \mathrm{MHz}$, and, finally, in Braşov 532, 666, and $802 \mathrm{MHz}$.

Subsequently, the man-made noise was evaluated for the three considered void channels. Man-made noise values that range up to $3 \mathrm{~dB}$ over the instrumentation noise level were obtained for the selected channels through a first analysis with $8 \mathrm{MHz}$ bandwidth filter. For this reason and also according to similar research [19], an occupancy threshold of $5 \mathrm{~dB}$ over the noise floor (i.e., $-75 \mathrm{dBm}$ at $8 \mathrm{MHz}$ ) was set. The values were confirmed by interpreting the normalized data measured with smaller bandwidth filters in the second and third measurement rounds (i.e., $1 \mathrm{MHz}$ and $100 \mathrm{kHz}$ bandwidths, respectively). 
TABLE 2: Characteristics of the antennas used for the measurements.

\begin{tabular}{lccccc}
\hline Model & Polarization & Type & Frequency range [MHz] & TX-Gain range [dBi] & RX-Gain range [dBi] \\
\hline PCB WA5VJB & Vertical & PCB log periodic & $400-1000$ & $0.2-4.2$ & $0.06-2.5$ \\
Schaffner CBL6143 & Vertical & X-Wing BiLog & $30-3000$ & $6-8$ & $6-8$ \\
Sirio SD 1300N & Vertical & Discone & $25-1300$ & $0-5.5$ & $0-6$ \\
BAF-121XSA2A & Vertical & Stub & $470-870$ & $0-2$ & $0-2$ \\
\hline
\end{tabular}

TABLE 3: Measurement system features.

\begin{tabular}{lccc}
\hline & Bilbao & Cagliari & Braşov \\
\hline $\begin{array}{l}\text { Field meter noise floor } \\
(\mathrm{dBm}, 1 \mathrm{~Hz})\end{array}$ & -150 & - & - \\
$\begin{array}{l}\text { Vector signal analyzer noise } \\
\text { floor }(\mathrm{dBm}, 1 \mathrm{~Hz})\end{array}$ & -155 & -149 & -149 \\
\hline
\end{tabular}

The evaluation of man-made noise with all the three bandwidths revealed the presence of higher noise levels in the considered urban environments with respect to the suburban and rural values. Furthermore, an increased noise level (up to $2 \mathrm{~dB}$ ) was noticed in the $800 \mathrm{MHz}$ band with respect to the $500 \mathrm{MHz}$ and $600 \mathrm{MHz}$ bands. This difference can be explained by the higher density of RF activity in the adjacent upper bands.

The measurements revealed also that the channel noise is above the equipment performances only for the urban scenarios. All three countries present similar noise level within the range of $\pm 0.5 \mathrm{~dB}$.

2.3. Sensing Bandwidth: $8 \mathrm{MHz}$ versus $1 \mathrm{MHz}$ and $100 \mathrm{kHz}$. The $8 \mathrm{MHz}$ bandwidth measurements provide the typical spectral information that a potential unlicensed device could achieve by using spectrum sensing techniques. The $1 \mathrm{MHz}$ and $100 \mathrm{kHz}$ measurements, which could provide higher accuracy, are unfeasible for typical unlicensed device implementations due to longer filter settling times. To mitigate the computational and time burden deriving from a hypothetical $1 \mathrm{MHz}$ or $100 \mathrm{kHz}$ sensing in a wide frequency range such as the $470-860 \mathrm{MHz}$, a selective approach has been followed by performing sampling within a typical $8 \mathrm{MHz} \mathrm{TV}$ channel at the central frequency of the channel and at two other symmetrical offsets with respect to the central frequency.

The gathered data have been deeply analyzed in order to identify the offsets: the $8 \mathrm{MHz}, 1 \mathrm{MHz}$, and $100 \mathrm{kHz}$ measurements were compared. Initially, the upper noise limits for the various scenarios for all three measuring bandwidths have been considered. The noise level at the three locations is around $-80 \mathrm{~dB}$ for $8 \mathrm{MHz}$ measurements, $-90 \mathrm{~dB}$ for $1 \mathrm{MHz}$ measurements, and $-100 \mathrm{~dB}$ for the $100 \mathrm{kHz}$ bandwidth. As expected, the upper noise limits drop with a mean value of around $10 \mathrm{~dB}$ for each considered measuring bandwidth.

Once the noise levels were obtained, we analyzed the amplitude of the various occupied TV channels with a signal level above the noise level, by subtracting the corresponding noise value for the $8 \mathrm{MHz}, 1 \mathrm{MHz}$, and $100 \mathrm{kHz}$ analysis. The channel power value for the $8 \mathrm{MHz}$ measurements was normalized with the scaling factor $7.61 \mathrm{MHz} / 1 \mathrm{MHz}$, where

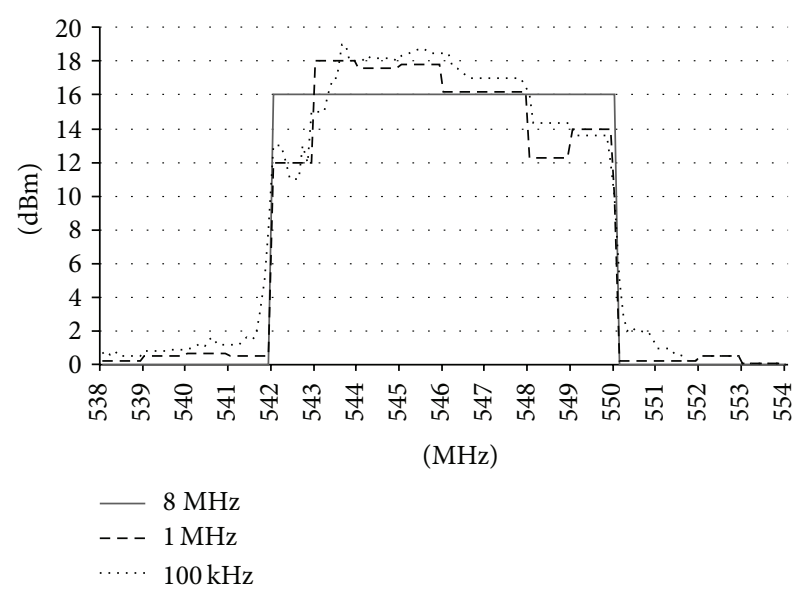

Figure 2: Comparison between the scaled signal power values $(\mathrm{dBm})$ for $8 \mathrm{MHz}$ and $1 \mathrm{MHz}$ measurements.

7.61 MHz is the $3 \mathrm{~dB}$ bandwidth of DTT signal. An example for DTT channel $30(546 \mathrm{MHz})$ can be seen in Figure 2.

It can be noticed that the values at $1 \mathrm{MHz}$ bandwidth differ up to $6 \mathrm{~dB}$ above or below the values at $8 \mathrm{MHz}$ bandwidth. The values at $100 \mathrm{kHz}$ bandwidth have the tendency to follow the $1 \mathrm{MHz}$ values within a range of $4 \mathrm{~dB}$ above and below. The tendency has been verified and confirmed also for other occupied channels, for different signal levels, for all scenarios, and for all measurements campaigns.

Analyzing the entire data set, we noticed a mean difference of $12 \%$ from the signal value above the noise floor, distributed as follows: for frequencies below the central frequency of a TV channel the measured power on a bandwidth of $1 \mathrm{MHz}$ and $100 \mathrm{kHz}$ is above the measured power level on an $8 \mathrm{MHz}$ bandwidth; contrarily, for frequencies above the central frequency of a TV channel the measured channel power on a bandwidth of $1 \mathrm{MHz}$ and $100 \mathrm{kHz}$ is below the measured channel power on an $8 \mathrm{MHz}$ bandwidth. The bigger negative variations towards the ends of the channels (the last $1 \mathrm{MHz}$ ) can be explained by the fact that the measured DTT signal has a $3 \mathrm{~dB}$ bandwidth of $7.61 \mathrm{MHz}$, with a guard band of $200 \mathrm{kHz}$ on both sides. On the other hand, $1 \mathrm{MHz}$ and $100 \mathrm{kHz}$ measurements on the central frequency of the TV channel present variation from the $8 \mathrm{MHz}$ measurements below $\pm 1 \mathrm{~dB}$.

Therefore, we concluded that both a $1 \mathrm{MHz}$ analysis and $100 \mathrm{kHz}$ analysis can be reasonably implemented by an unlicensed device in a TV channel, by considering only three samples per channel: at the channel center frequency and below and up the center frequency with an offset of 


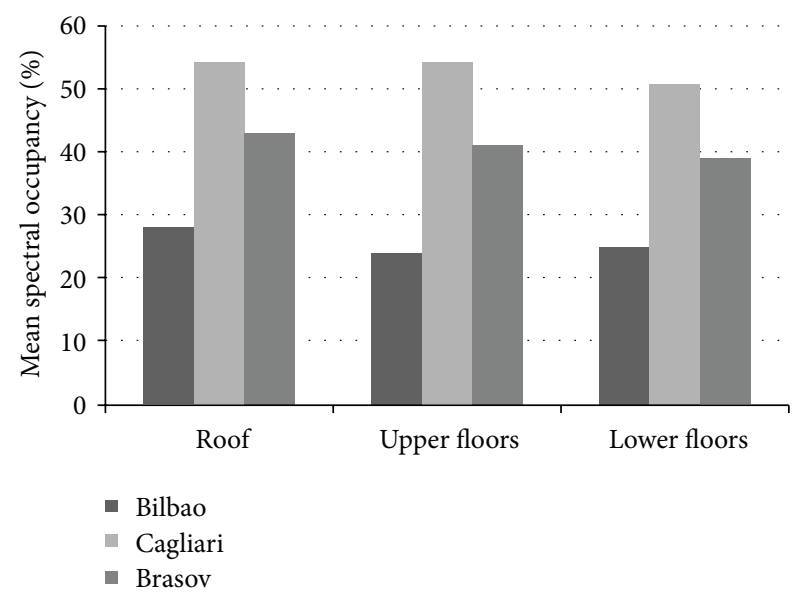

Figure 3: Mean spectral occupancy for the three cities in urban environment.

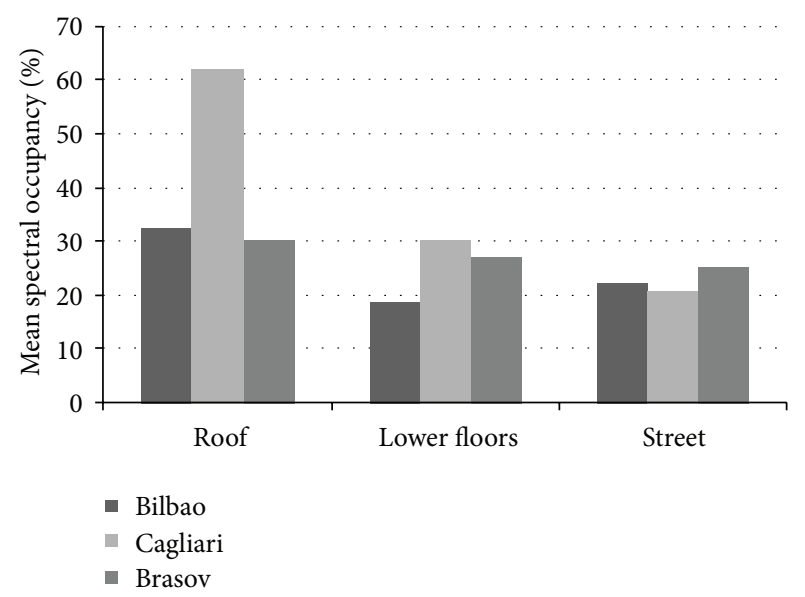

FIGURE 4: Mean spectral occupancy for the three cities in suburban environment.

$3 \mathrm{MHz}$. The $100 \mathrm{kHz}$ analysis is by default to be more precise due to the lower noise floor, so if there are no hardware constraints, even such a narrow bandwidth could be used by an unlicensed device for performing accurate spectrum sensing operations.

\section{Results}

3.1. Spectral Occupancy. The measurements carried out in different scenarios and reception environments (i.e., roof, upper floors, lower floors, and street) lead to a clear picture in terms of the mean spectral occupancy for the three cities. Figures 3, 4, and 5 show the mean spectral occupancy values, expressed as percentages, in urban, suburban, and rural environment, respectively.

The three figures demonstrate that the UHF band occupation in Cagliari is on average higher than the ones for Bilbao and Brassov. This result is motivated by the differences between the Italian, the Spanish, and the Romanian TV market. In the last years, the use of the spectrum in Italy has been

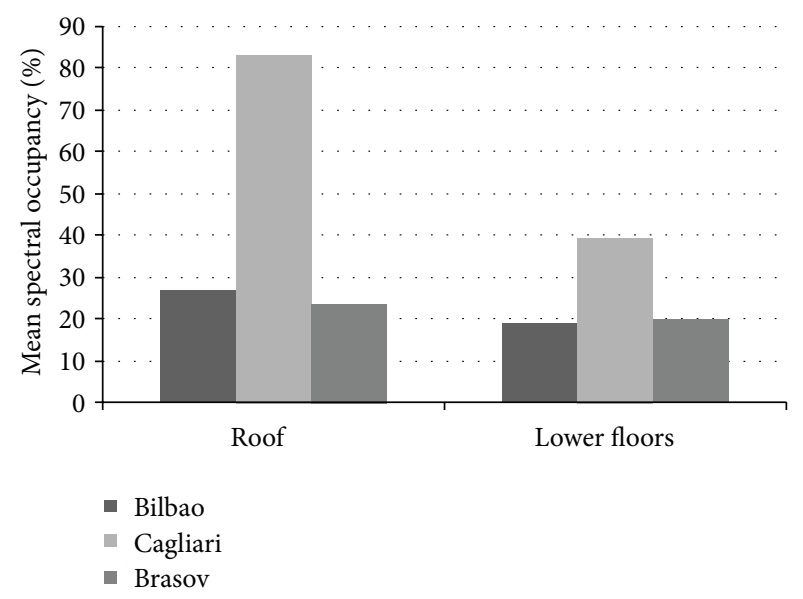

FIGURE 5: Mean spectral occupancy for the three cities in rural environment.

increased by numerous private TV broadcasters offering both free-to-air and pay-per-view services. The exact opposite can be observed in Braşov, where the digital switchover is still in an incipient stage with a steady presence of analog TV services [30]. Nevertheless, Figure 3 shows a relatively high spectral occupancy in Braşov, due to the intrinsic higher interference of analog TV signals which present extended spectral side lobes. Indeed, this result is only noticeable in urban areas, where local TV channels are more frequent with respect to the suburban and rural scenarios.

The same consideration, but in a smaller proportion, can be applied also for the Spanish location, situated at the time of the measurements in the middle of the digital switchover process, with still a large amount of analog TV services.

For all locations, the spectral occupancy in urban environment remains constant from the roof of the buildings to the lower floors, while the difference in the occupancy measured on the roof and the lower floors is more accentuated in rural scenario.

Comparing the roof case for Figures 3, 4, and 5, the mean spectral occupancy decays gradually from the urban to the rural scenario, apart from the city of Cagliari. This result can be explained considering that the Italian rural scenario is characterized by large open spaces allowing the reception with rooftop antennas of signals from more than one broadcast repeater. For the same reason, the rooftop values obtained in Italy represent more than double the occupancy measured inside a rural home.

For the rural scenario, the values for the spectral occupancy in Bilbao and Brașov are similar due to the similar orography of the considered locations, surrounded by steep hills that do not offer good propagation conditions.

3.2. Hidden Node Margin. The HNM is based on the practical observation that primary TV signals are mostly received by rooftop antennas whereas unlicensed devices analyze the spectrum picture locally, at different elevations. This means that an unlicensed device performing spectrum sensing 
TABLE 4: Hidden node margin for $\%$ of locations in the three considered frequency bands.

\begin{tabular}{lccccccccc}
\hline Band & \multicolumn{3}{c}{$500 \mathrm{MHz}$} & \multicolumn{3}{c}{$600 \mathrm{MHz}$} & \multicolumn{3}{c}{$800 \mathrm{MHz}$} \\
Scenario & $90 \%$ & $95 \%$ & $99 \%$ & $90 \%$ & $95 \%$ & $99 \%$ & $90 \%$ & $95 \%$ & $99 \%$ \\
\hline Rural & 15.2 & 24.1 & 29.2 & 17.1 & 26.2 & 30.1 & 19.1 & 28.3 \\
Suburban & 15.3 & 20.1 & 24.1 & 17.6 & 21.3 & 26.3 & 19.7 & 22.5 \\
Urban & 8.5 & 13.0 & 21.6 & 10.3 & 15.1 & 23.6 & 14.1 & 17.3 & 28.2 \\
\hline
\end{tabular}

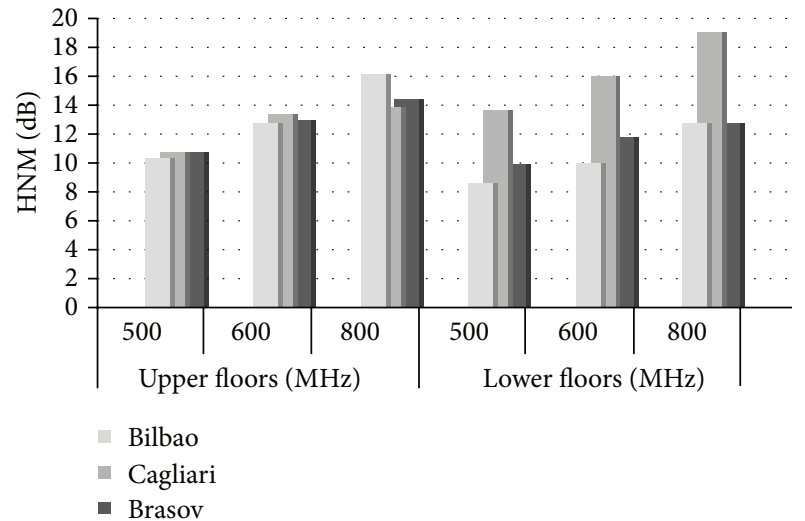

Figure 6: HNM for the three cities in urban environment.

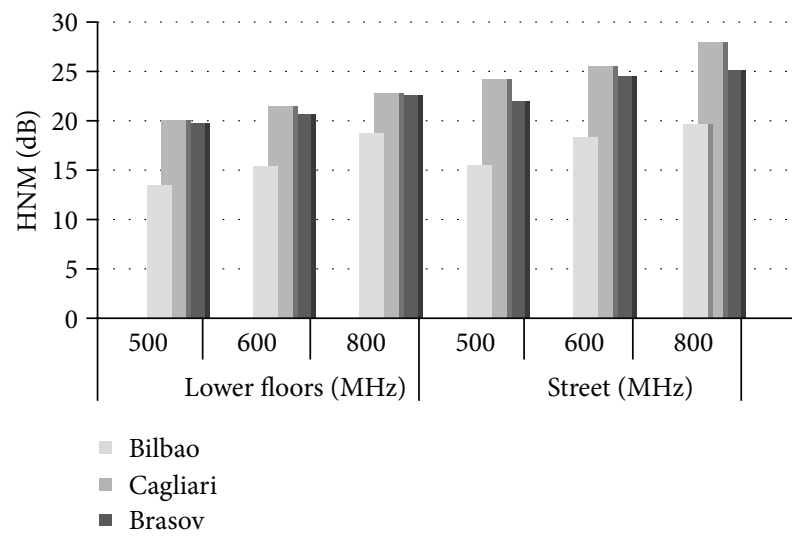

FIGURE 7: HNM for the three cities in suburban environment.

might not be able to detect the existing primary services due to shadowing, thus potentially causing interference [16].

The HNM is calculated as the difference of the signal power measured on the roof and all the power values measured at each floor of the buildings for indoor scenarios and at street level for outdoor scenarios.

Different from the previous work and also from other measurements found in the literature, we performed the analysis of the HNM separately on three frequency bands, $500 \mathrm{MHz}, 600 \mathrm{MHz}$, and $800 \mathrm{MHz}$, for a more accurate characterization of the HNM problem. The aggregated HNM values for the three countries are presented in Figures 6, 7, and 8 grouped by environment and divided by frequency bands.

The average values of the HNM range from 8 to $38 \mathrm{~dB}$ with a sensible variation depending on the buildings, the floor number, and the receiving environment. In urban

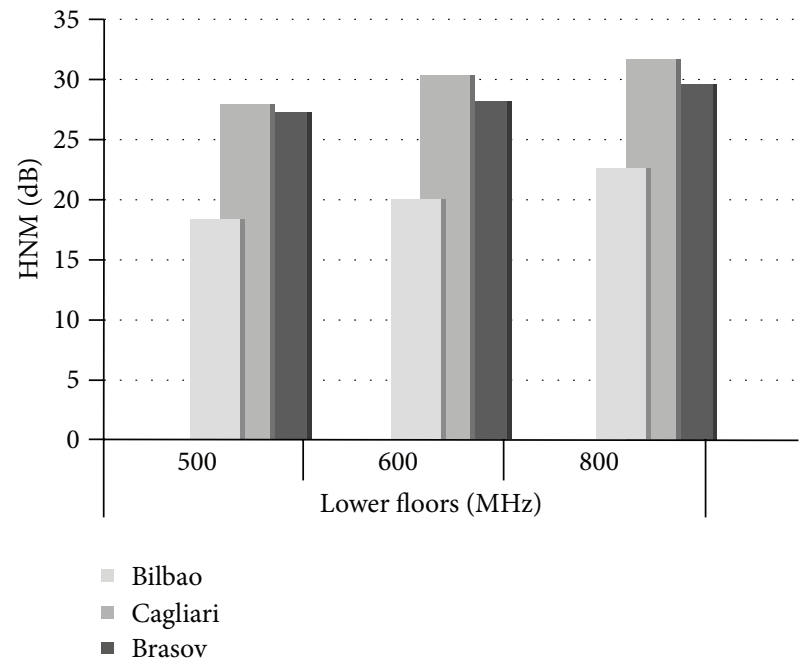

FiguRE 8: HNM for the three cities in rural environment.

environments the HNM decays gradually with the distance from the roof, for each floor of the buildings. The Italian scenario shows larger HNM compared to the Spanish and Romanian measurements.

A smoother variation is noticeable for the HNM in urban areas with respect to the suburban and rural scenarios. This behavior can be explained by the topology of the dense urban environments populated with tall buildings which produce an important amount of attenuation.

Table 4, which presents the numerical values of a cumulative distribution, shows overall differences in the range of $\pm 5 \%$ for the channels on which the measurements were performed.

Figures 6, 7, and 8 and Table 4 show also a difference for the HNM values in the range of $\pm 2 \mathrm{~dB}$ between the three frequency bands $(500,600$, and $800 \mathrm{MHz})$ : the values for the HNM in the $500 \mathrm{MHz}$ band are around $2 \mathrm{~dB}$ lower than the ones calculated for the $600 \mathrm{MHz}$ band. The difference is similar between the $600 \mathrm{MHz}$ and the $800 \mathrm{MHz}$ bands. These differences are constant for all scenarios and all countries and therefore can be only explained by the variation of the propagation conditions which are better for lower frequencies, making the signal power difference between the rooftop measurements and the floor measurements smaller.

\section{Conclusions}

This paper presented an extended measurement campaign of the UHF TV bands IV and V (470-860 MHz) performed in 
urban, suburban, and rural locations in and around the cities of Bilbao (Spain), Cagliari (Italy), and Brașov (Romania) to obtain realistic values of the parameters (i.e., occupancy threshold, sensing bandwidth, and HNM) to assess the feasibility of unlicensed harmless communication in the TV white spaces.

Results have shown a mean occupancy for the three cities of $32 \%$ with a standard deviation of 18 by using an occupancy threshold of $-75 \mathrm{dBm}$ at $8 \mathrm{MHz}$. A top occupancy of $84 \%$ of the bandwidth has been measured with rooftop antennas in rural areas, where the coverage areas from different repeaters overlap due to the lack of obstacles.

In terms of sensing bandwidth, the measured data confirms the results presented by the reviewed studies [9-11] that sensing alone does not solve the HNM problem if the used sensing bandwidths are higher than $1 \mathrm{MHz}$. In this sense, the results provide guidelines for the resolution bandwidths and measurement processing methodology required for obtaining values that can be used, for example, to populate GL-DBs databases.

The measurements of the man-made noise in the UHF TV bands have shown that noise is below the equipment performances with the exception of the urban scenarios where the presence of noise could be measured.

The analysis of the feasibility on using $1 \mathrm{MHz}$ and $100 \mathrm{kHz}$ sensing bandwidths for unlicensed devices showed that this can be achieved by reducing the sampling operations to only three readings per $8 \mathrm{MHz}$ channel.

The evaluation of the obtained HNM values revealed variations from 8 to $38 \mathrm{~dB}$ depending on the environment. Also, a constant variation within the limit of $4 \mathrm{~dB}$ of the HNM depending on the frequency was noted, with smaller HNM values for lower frequencies within the UHF band.

\section{Conflict of Interests}

The authors declare that there is no conflict of interests regarding the publication of this paper.

\section{Acknowledgment}

The research activities described in this paper have been conducted within the Researchers Project titled Opportunistic Vehicle to Grid Communications in the UHF Band developed at the CNIT Cagliari Research Unit, funded by Region of Sardinia, P.O.R. SARDEGNA F.S.E. 2007-2013 Obiettivo Competitività Regionale e Occupazione, Asse IV Capitale Umano, Linee di Attività 1.1.1. e 1.3.1.

\section{References}

[1] M. Nekovee, "A survey of cognitive radio access to TV white spaces," International Journal of Digital Multimedia Broadcasting, vol. 2010, Article ID 236568, 11 pages, 2010.

[2] M. Murroni, S. Scalise, A. Vanelli-Coralli, S. Kim, and R. Briskman, "Convergence of digital TV systems and services," International Journal of Digital Multimedia Broadcasting, vol. 2009, Article ID 817636, 3 pages, 2009.
[3] FCC, "FCC Second Memorandum Opinion and Order10-174," 2010, http://hraunfoss.fcc.gov/edocs_public/attachmatch/FCC10-174A1.pdf.

[4] R. Gandhiraj and K. P. Soman, "Modern analog and digital communication systems development using GNU Radio with USRP," Telecommunication Systems, vol. 56, no. 3, pp. 367-381, 2013.

[5] ETSI RRS-TR 103 067, "Feasibility study on Radio Frequency (RF) performances for Cognitive Radio Systems in UHF TV Band White Spaces," 2013, http://www.etsi.org/deliver/etsi_ tr/103000_103099/103067/01.01.01_60/tr_103067v010101p.pdf.

[6] M. Fadda, M. Murroni, and V. Popescu, "An unlicensed indoor HDTV multi-vision system in the DTT Bands," IEEE Transactions on Broadcasting, vol. 58, no. 3, pp. 338-346, 2012.

[7] M. Laddomada, H. H. Chen, F. Daneshgaran, M. Mondin, and H. Sadjadpour, "Spectrum sharing and sensing for future broadband networks: the cognitive radio technology," International Journal of Digital Multimedia Broadcasting, vol. 2010, Article ID 898470, 2 pages, 2010.

[8] M. Murroni, R. V. Prasad, P. Marques et al., "IEEE 1900.6: spectrum sensing interfaces and data structures for dynamic spectrum access and other advanced radio communication systems standard," IEEE Communications Magazine, vol. 49, no. 12, pp. 118-127, 2011.

[9] M. Fadda, M. Murroni, C. Perra, and V. Popescu, "TV white spaces exploitation for multimedia signal distribution," Signal Processing: Image Communication, vol. 27, no. 8, pp. 893-899, 2012.

[10] K. Arshad, M. A. Imran, and K. Moessner, "Collaborative spectrum sensing optimisation algorithms for cognitive radio networks," International Journal of Digital Multimedia Broadcasting, vol. 2010, Article ID 424036, 20 pages, 2010.

[11] M. Sanna and M. Murroni, "Nonconvex optimization of collaborative multiband spectrum sensing for cognitive radios with genetic algorithms," International Journal of Digital Multimedia Broadcasting, vol. 2010, Article ID 531857, 12 pages, 2010.

[12] M. Waddell, "Compatibility challenges for broadcast networks and white space devices," White Paper WHP 182, BBC, 2010, http://www.bbc.co.uk/blogs/legacy/bbcinternet/mw_doanloads/ IBC09_WSD_Compatibility_vla.pdf.

[13] L. Tang, Q. Chen, G. Wang, X. Zeng, and H. Wang, "Opportunistic power allocation strategies and fair subcarrier allocation in OFDM-based cognitive radio networks," International Journal on Telecommunication Systems, vol. 52, no. 4, pp. 20712082, 2013.

[14] ECC Report 159, “Technical and operational requirements for the possible operation of cognitive radio systems in the white spaces of the frequency band 470-790 Mhz," Tech. Rep., 2011.

[15] P. Torío and M. G. Sánchez, "Reconciling the ETSI coverage requirements for DVB-T with the ITU-R recommendations," Telecommunication Systems, vol. 57, no. 3, pp. 217-222, 2013.

[16] M. Fadda, M. Murroni, V. Popescu, P. Angueira, J. Morgade, and M. Sanchez, "Hidden node margin and man-made noise measurements in the UHF broadcasting bands," in Proceedings of IEEE International Symposium on Broadband Multimedia Systems and Broadcasting (BMSB '12), pp. 1-5, Seoul, Republic of Korea, June 2012.

[17] M. Barbiroli, C. Carciofi, A. Guidotti, and D. Guiducci, "Evaluation and analysis of the hidden node margin for cognitive 
radio system operation in a real scenario," in Proceedings of the 5th European Conference on Antennas and Propagation (EUCAP '11), pp. 1309-1313, Rome, Italy, April 2011.

[18] B. S. Randhawa, Z. Wang, and I. Parker, "Report Title: Analysis of hidden node margins for cognitive radio devices potentially using DTT and PMS spectrum," 2009, http://stakeholders.ofcom.org.uk/binaries/spectrum/spectrumpolicy-area/projects/ddr/eracog.pdf.

[19] L. Liu, Z. Li, and C. Zhou, "Backpropagation-based cooperative localization of primary user for avoiding hidden-node problem in cognitive networks," International Journal of Digital Multimedia Broadcasting, vol. 2010, Article ID 905321, 9 pages, 2010.

[20] Y. Han, Y. Wen, W. Tang, and S. Li, "Spectrum occupancy measurement: focus on the tv frequency," in Proceedings of the 2nd International Conference on Signal Processing Systems (ICSPS '10), vol. 2, pp. 490-494, Dalian, China, July 2010.

[21] R. A. Rahim, R. Nordin, and M. Ismail, "Investigation of channel bonding based on TV White Space spectrum occupancy for urban areas in Malaysia," in Proceedings of the 2nd International Conference on Information and Communication Technology (ICoICT '14), pp. 100-105, Bandung, Indonesia, May 2014.

[22] S. Contreras, G. Villardi, R. Funada, and H. Harada, "An investigation into the spectrum occupancy in Japan in the context of TV White Space systems," in Proceedings of the 6th International ICST Conference on Cognitive Radio Oriented Wireless Networks and Communications (CROWNCOM '11), pp. 341-345, Yokosuka, Japan, June 2011.

[23] M. López-Benítez, A. Umbert, and F. Casadevall, "Evaluation of spectrum occupancy in Spain for cognitive radio applications," in Proceedings of the 69th IEEE Vehicular Technology Conference (VTC Spring '09), pp. 1-5, Barcelona, Spain, April 2009.

[24] R. I. C. Chiang, G. B. Rowe, and K. W. Sowerby, "A quantitative analysis of spectral occupancy measurements for cognitive radio," in Proceedings of the IEEE 65th Vehicular Technology Conference (VTC '07), pp. 3016-3020, Dublin, Irelan, April 2007.

[25] M. López-Benítez, F. Casadevall, A. Umbert et al., "Spectral occupation measurements and blind standard recognition sensor for cognitive radio networks," in Proceedings of the 4th International Conference on Cognitive Radio Oriented Wireless Networks and Communications (CROWNCOM '09), pp. 1-9, Hannover, Germany, June 2009.

[26] A. Palaios, J. Riihijärvi, P. Mähönen et al., "Two days of spectrum use in Europe," in Proceedings of the 7th International ICST Conference on Cognitive Radio Oriented Wireless Ntworks and Communications (CROWNCOM '12), pp. 24-29, Stockholm, Sweden, June 2012.

[27] A. Kliks, P. Kryszkiewicz, J. Pérez-Romero, A. Umbert, and F. Casadevall, "Spectrum occupancy in big cities-comparative study-measurement campaigns in Barcelona and Poznan," in Proceedings of the 10th International Symposium on Wireless Communication Systems (ISWCS '13), pp. 1-5, Ilmenau, Germany, August 2013.

[28] P. I. Lazaridis, S. Kasampalis, Z. D. Zaharis et al., "UHF TV band spectrum and field-strength measurements before and after analogue switch-off," in Proceedings of the 4th International Conference on Wireless Communications, Vehicular Technology, Information Theory and Aerospace \& Electronic Systems (VITAE '14), pp. 1-5, Aalborg, Denmark, May 2014.
[29] K. Chen, J. Min, X. Han, and X. Yan, "Spectrum survey for TV band in Beijing," in Proceedings of the 21st International Conference on Telecommunications (ICT '14), vol. 2014, pp. 267271, Lisbon, Portugal, May 2014.

[30] C. Verikoukis, I. Konstas, D. Anastasiadou, and P. Angelidis, "Overview on telecommunications regulation framework in South-Eastern Europe," Telecommunication Systems, vol. 32, no. 2-3, pp. 209-221, 2006. 

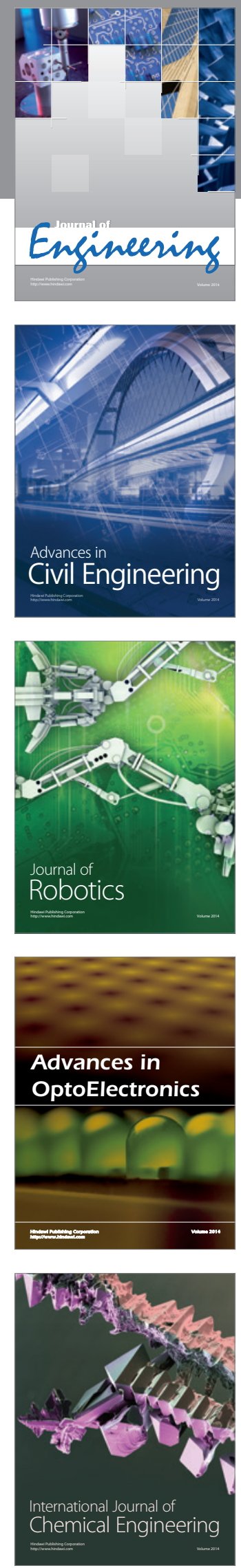

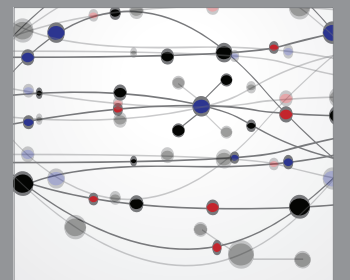

The Scientific World Journal
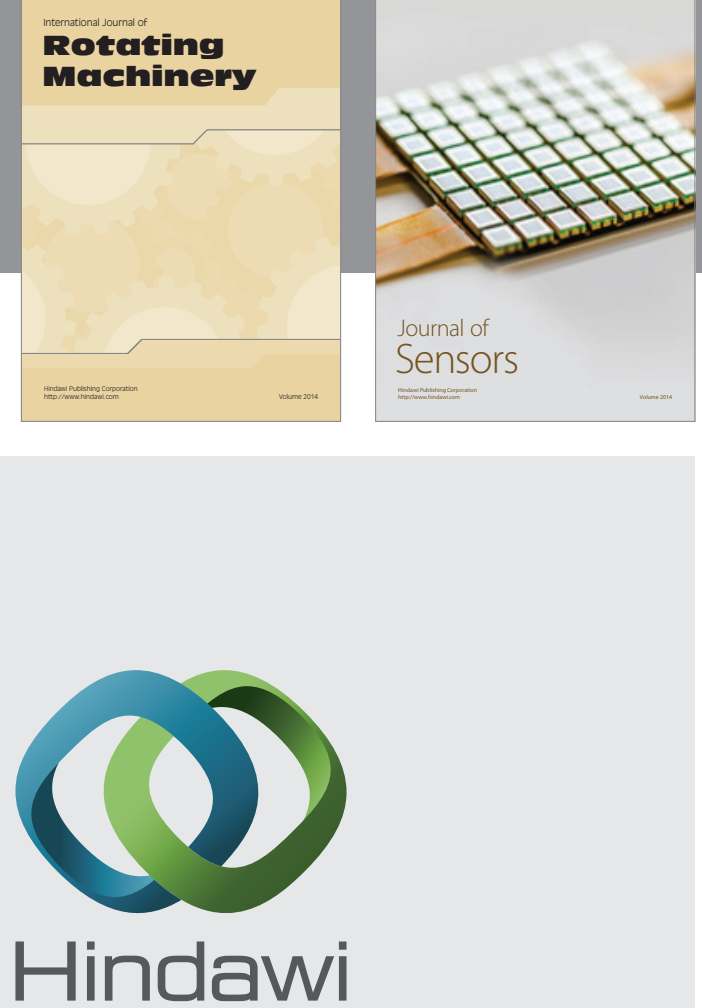

Submit your manuscripts at http://www.hindawi.com
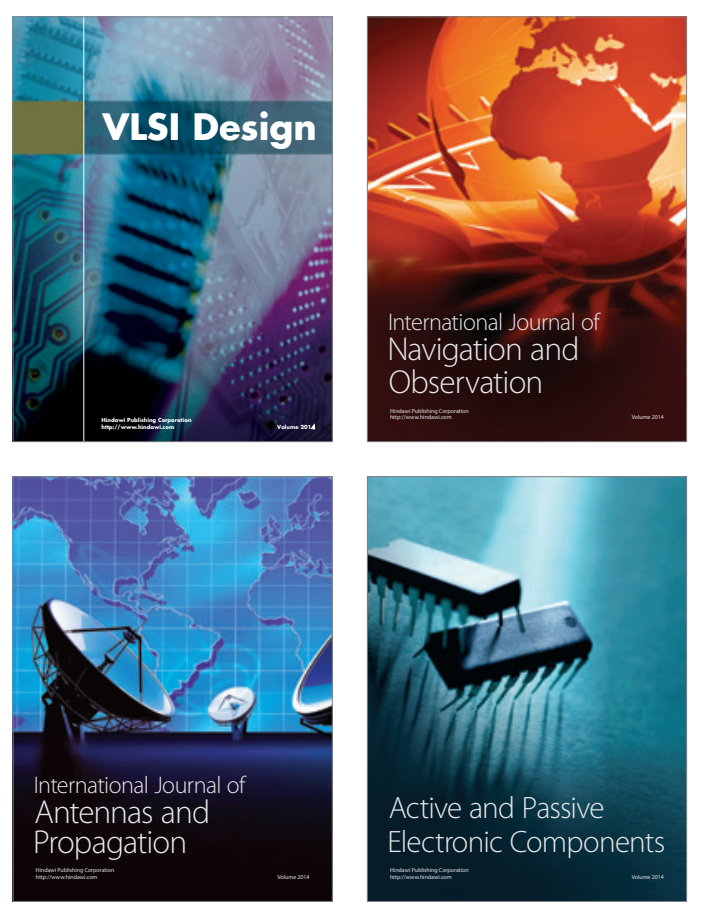
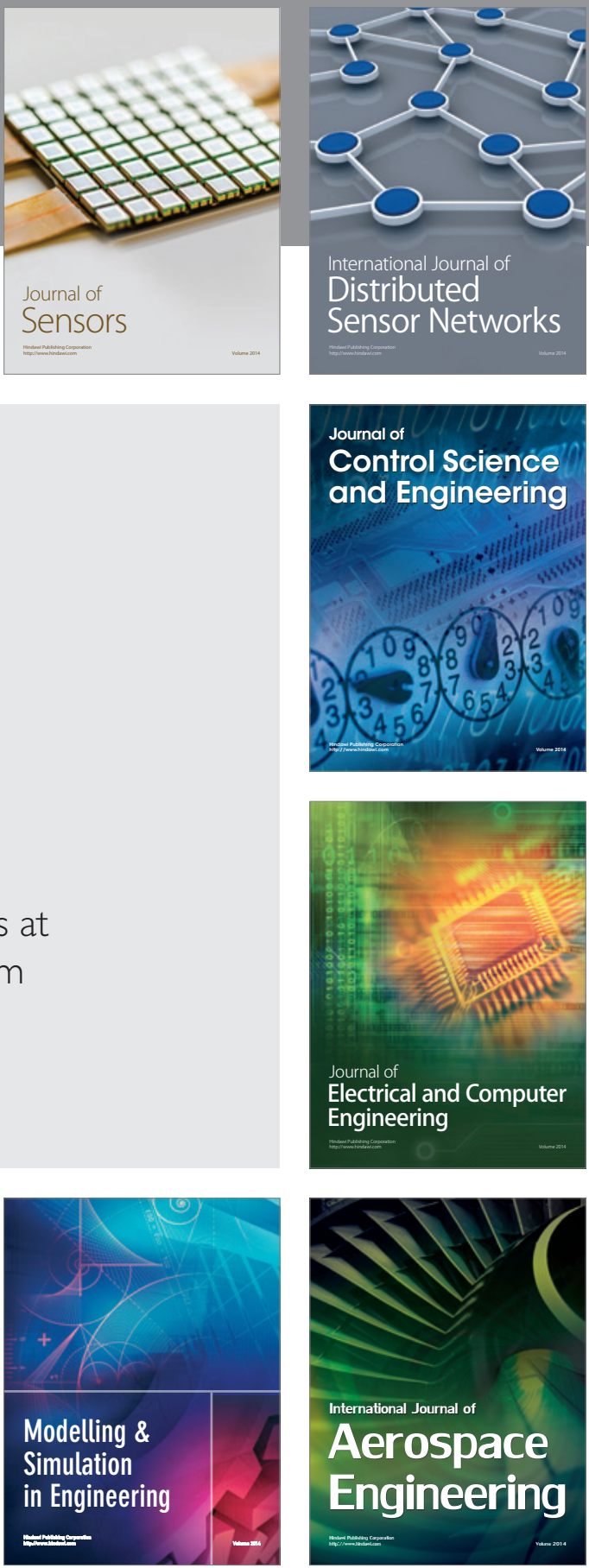

Journal of

Control Science

and Engineering
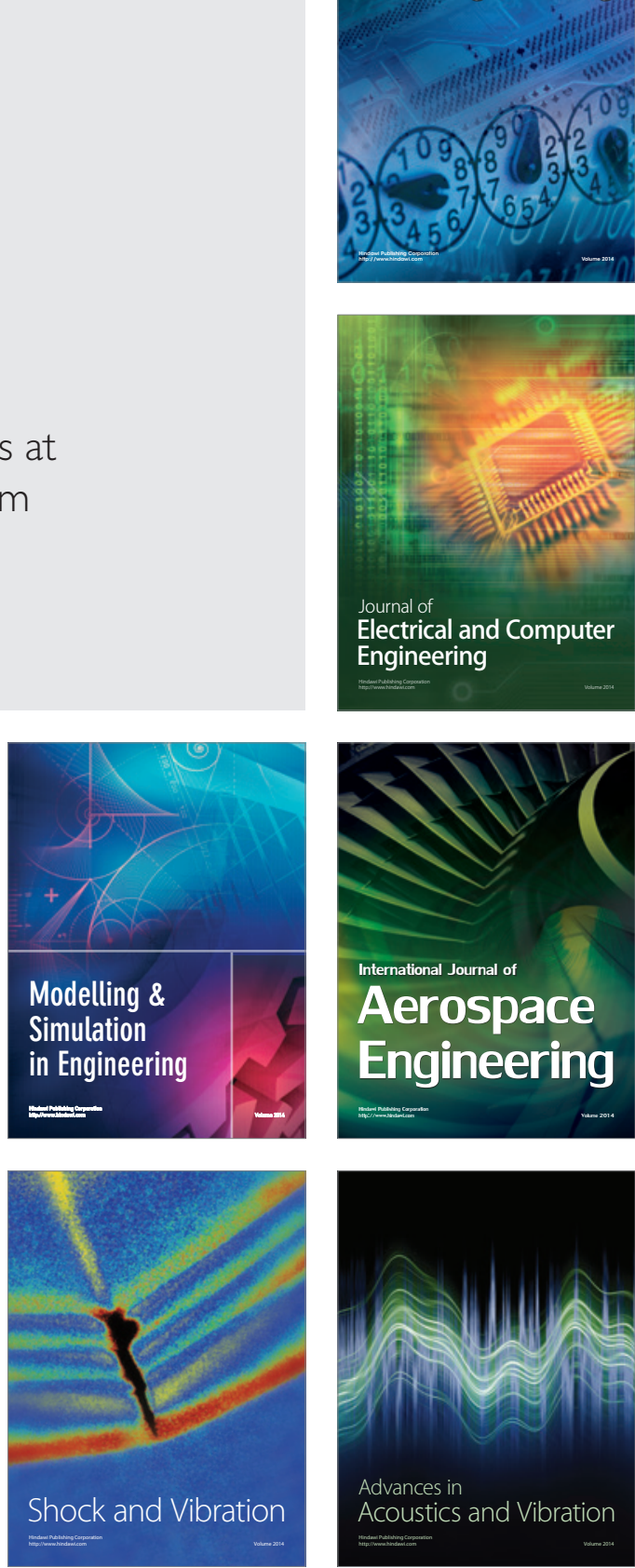